\title{
PRESERVICE TEACHERS' ADOPTION OF A MAKERSPACE
}

\author{
Junko Yamamoto \\ Slippery Rock University of Pennsylvania, United States of America
}

\begin{abstract}
Innovation includes new inventions, new ideas, or new methods. Everett Rogers' Diffusion of Innovations framework, however, suggests not all are willing to adopt innovation. Technology Acceptance Model (TAM) indicates that perceived usefulness and perceived ease of use influence one's choice to use available technology. Since the nature of work is rapidly changing, the future workforce needs to be prepared to innovate or adopt innovation. This means that educators also need to be innovators or early adopters. In this study, education majors in an instructional technology class in the United States were introduced to the idea of a makerspace. When they were given choices, some participants tried new tools or methods without the instructor's assistance, and some tried with the assistance. However, there was also a group of education majors who chose not to try out new tools or methods, even they knew that the help was available. This finding implies that Rogers' theory about people's aptitude of adopting innovation and TAM are applicable to future educators.
\end{abstract}

\section{KEYWORDS}

Teacher Education, Makerspace, Adoption, Diffusion of Innovation, Technology Acceptance Model

\section{INTRODUCTION}

Teachers are tasked to prepare their students to be successful in the workforce for a lifetime. Since society and the required skills change rapidly, lifelong learning, creativity, innovation, and adaptation of new ideas needs to be embedded in instructional strategies. Learners need to develop an aptitude for dealing with uncertainty, and to make a mental effort to acquire new skills. In order to facilitate classroom activities that stimulate creativity and innovation, teachers need to be prepared and willing to teach themselves as new methods, ideas, and tools are presented to them. Consequently, the International Society for Technology in Education (ISTE) published the 2017 Standards for Educators that expect teachers to be able to facilitate activities that nurture creativity and innovation (International Society for Technology in Education, 2017).

The idea that the education should prepare a future workforce is not new. For example, Trilling and Fadel published a book about 21st Century skills in 2009. In the book, they stated that the nature of work has changed from routine manual or routine cognitive work to being more reliant upon expert thinking. According to Trilling and Fadel (2009), schools need to teach critical thinking, creativity, collaboration, communication, information literacy, media literacy, technology literacy, and flexibility. Routine jobs are more likely to be replaced by artificial intelligence than jobs that require expert thinking and creativity. The Implication being that a future workforce needs to be innovative. Since the book was published in 2009, society has indeed witnessed routine works, such as cash register checkout and highway toll payment, being replaced by machines. Hence, schools need to educate students to be innovative, and also to quickly adopt innovation.

Innovation refer to creating something new, which can be a new idea, designing new ways of completing a task, or making something that no one has made before. Innovation does not have to involve technology (Krueger, 2019). Designing and making something new, using digital or non-digital tools and materials promotes a leaner's innovative ability. Likewise, using a tool in a way that no one has used it before, even if the tool has been available for a long time, qualifies as an innovation.

Working with hands to create something new stimulates brain (McQuinn, 2018) and it promotes creativity and innovation. Because of it, the maker space movement has gained momentum in the United States. 
Although 3D printers, cutting machines, and robotics kits are found in a makerspace, digital technology is not required for a maker space. Conventional tools such as a sewing machine (Mann, 2018) and woodworking tools can also be a part of a maker space. The purpose of this paper is to show how future teachers can use a makerspace to convert an abstract concept into a concreate visual product.

\section{BODY OF PAPER}

\subsection{Literature Review}

\subsubsection{ISTE Standard}

Teacher education is often driven by standards. Standards for teacher education function as accountability measures, ensuring that educators are preparing teacher candidates to have the ability to successfully prepare the future generations for their jobs (Chung \& Kim, 2010). Aligning instruction to standards in teacher preparation also demonstrates a high quality teacher education (Murray, 2001). ISTE Standards for Educators includes categories such as "Designer: Educators design authentic, learner-driven activities and environments that recognize and accommodate leaner variability," and "Facilitator: Educators facilitate learning with technology to support student achievement of the ISTE Standards for Students" These standards call for creating personalized learning experiences, designing authentic learning activities, encouraging independent learning, challenging learners to use the design process, and modeling creativity (ISTE, 2017).

\subsubsection{Makerspace}

One of the elements captured in these standards can be facilitating creativity through a utilization of a makerspace. A makerspace is a space that students can create digital or physical objects to express their understanding. Students share materials and collaborate in the space (Trust, Maloy, \& Edwards, 2018). Making does not need to involve technology: students can make their mental representation models or prototype of a product using common materials, such as cardboard and duct tape (Maughan, 2018). The concept of maker space is more about the act of making, rather than a physical space (Trust, Maloy, \& Edwards, 2018). Technology integration in classrooms has shifted from teacher-centered models to student-centered models (Mulienburg \& Berge, 2015; Passehl-Stoddart, Velte, Henrich, \& Gaines, 2018), and makerspace is in line with a student-centered approach.

Designing a makerspace does not start with which tools to use, but rather with what is desirable for learners to accomplish. For example, rather than thinking, "we must use a 3D printer," and forcing technology onto an educational setting, the designer should think, "I would like my learners to create a 3D model." When multiple tools are available, and learners choose what they want to use, the technology integration is at the infusion level according to the Technology Integration Matrix (https://fcit.usf.edu/matrix/matrix/). When a teacher sets up the context, and students determine which tools to use, the technology use realizes "resource fluency" (Muilenburg \& Berge, 2015). Choosing tools should be left up to a learner. When a teacher assigns students to create a 3D model that moves, students should have a choice to use a variety of tools, such as cardboard with Hummingbird, Lego EV3, or wood combined with metal and rubber.

\subsubsection{Theoretical Framework: Diffusion of Innovation and Technology Acceptance Model}

Teachers' willingness to try something new is important for creating a learner-driven environment. Unfortunately, the availability of new ideas, resources, or tools does not automatically warrant their use by the majority of the population. Many innovations require a lengthy period from when it becomes available to when they are adopted. In other words, not all people adopt innovations when they become available. Some choose not to use tools at all. In general, $2.5 \%$ of a population are innovators. Only about $10 \%-25 \%$ of a population are earlier adopters of an innovation. (Rogers, 1983). Rogers (1983) explain that 13.5\% of a population adopt an innovation at early stage. Then next $34 \%$ are the early majority. It is followed by the late majority, which make up for $34 \%$. Finally, $16 \%$ of the population is the laggards (p.246-247). Although 
Rogers published the book decades ago, human nature has not changed. There are some individuals that are interested in learning something new, and there are those who resist changes.

Diffusion is the process in which an innovation is communicated and adopted. Individuals go through an innovation-decision process to decide if they want to adopt or reject new ideas, resources, or technology tools. The innovation-decision process commands mental work. Adopters need to cope with uncertainty and need to have the motivation to seek out innovation. Level of education and social status may affect the attitude to adopt innovation, but age is not an influential factor. In addition, earlier adopters have greater ability to deal with abstraction, and have greater rationality than later adopters (Rogers, 1983).

The Technology Acceptance Model (TAM) explains the diffusion of innovation through the lens of who is willing to adopt the technology. The availability of technology does not automatically result in its adoption. There are two factors of innovation that must be considered for the technology to be adopted: perceived usefulness and perceived ease of use. Self-efficacy, or belief that they can succeed on a task, influences perceived ease of use (Davis, 1989). Self-efficacy involves motivation, cognition, and self-regulation. Those with high self-efficacy tend to be more willing to take risks, and keep trying when they experience difficulties. On the other hand, those who doubt their ability to cope with a task shy away from it (Bandura, 1994). In fact, self-efficacy plays a key role in an educator's decision to adopt technology (Joo, Park, \& Lim, 2018).

Perceived usefulness and perceived ease of use increase an educator's willingness to adopt a new technology tool (Flavell et al., 2019; Kukul, Ünal, Karataş, Çakmak, Yılmaz, \& Ömeroğlu, 2018; Shittu, Kareem, Objelodan, \& Fakomogbon, 2017). Furthermore, those who enjoy challenges may be more willing to try something new (Flavell et al., 2019). Teachers' psychological factors, ranging from a willingness to take risks, fear of failure, a lack of confidence, and general technology anxiety influence perceived usefulness and perceived ease of use (Flavell, Harris, Price, Logan, \& Peterson, 2019). Figure 1 shows the Technology Acceptance Model.

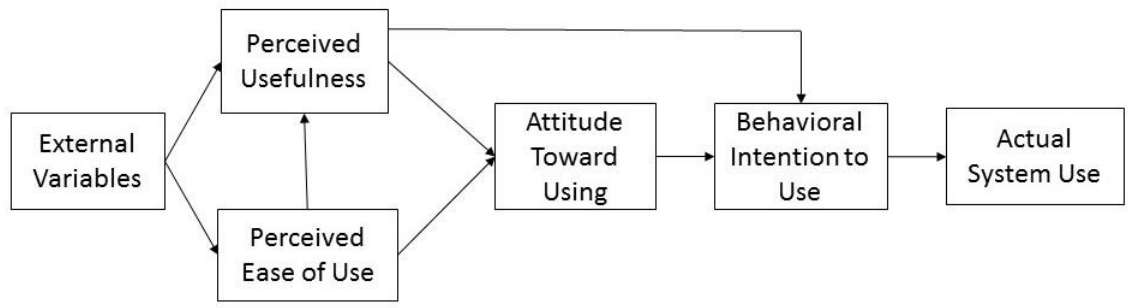

Figure 1. Technology Acceptance Model (TAM) (Davis, Bagozzi, \& Warshaw, 1989, p. 985)

\subsection{Research Questions}

Research questions include:

1. Do education majors increase their knowledge about makerspace after the instruction?

2. What type of tools do research participants choose to use?

3. Will there be research participants who use tools that they have never used without the instructor's assistance?

4. Will there be research participants who use tools that they have never tried with the instructor's assistance?

5. Will there be research participants who does not use tools that they have never used even when assistance is available?

6. Do perceived usefulness and perceived ease of use influence the decision to use new tools? 


\subsection{Methods}

\subsubsection{Research Participants}

Research participants were preservice teachers who were enrolled in an undergraduate level instructional technology class in a teacher preparation program in the United States of America during the fall 2018 semester. There were 26 who participated in this study. The participants included 4 Middle Level (Grade 4-8) Math Education majors, 3, Middle Level (Grade 4-8) Science Education majors, 2 Middle Level (Grade 4-8) English Education majors, 6 Secondary (Grade 7-12) English Education Majors, 6 Secondary (Grade 7-12) Social Studies Education majors, 2 French Education Majors, 1 double major of Secondary English Education and French Education, 1 Art Education major, and 1 Pre-Math Education major.

There were 10 freshmen, 11 sophomores, 2 juniors, 1 senior, and 2 post baccalaureate students. In this teacher preparation program, students take the instructional technology class before they take a teaching methodology class. Also, a typical semester schedule of a freshman or a sophomore is populated by general education courses, or courses that any majors would take. Hence, they have taken a limited number of content area courses and/or pedagogy courses prior to the study.

\subsubsection{Instruments}

A Likert-type survey was used with the following statements:

- I know what a makerspace is.

- I know how to design makerspaces.

- I know how to use a makerspace.

Value assigned to the self-evaluation were:

Strongly Agree = 5; Agree = 4; Neither Agree or Disagree = 3; Disagree = 2; Strongly Disagree $=1$

A T-test was used to calculate the mean difference between the pre-instructional survey and post-instructional survey. This instrument was used for research question 1.

Moreover, participants wrote reflections with these prompts:

- "Which tools did you choose?" This prompt was used for research question 2.

- "Why did you use the tools?" This question was used to determine participants' beliefs about the usefulness and ease of use.

- "Did you know how to use the tools?" This question was asked to find out participants' levels of self-efficacy regarding new tools.

- "Did you decide to use the tools because you saw it being used during the project explanation?" This question was asked to find out if participants perceived the usefulness of tools when they saw the instructor model the use before the participants decided which tools to use.

- "How do you rate yourself about exploring new tools and learning how to use them? Elaborate your answer." This question examines participants' attitudes about willingness to learn new tools.

Kukul et al. (2018) used an interview form for data collection.

\subsubsection{Instruction}

The participants were introduced to the concept of makerspace and used a makerspace for two seventy-five-minute class sessions. After they used the makerspace, they presented their products to peers and explained to them what they represented. Idealistically, the future teachers were to create a teaching material in their instructional technology class. However, with 21 out of 26 research participants being freshmen and sophomores, the instruction needed to adjust according to the prior content and pedagogical knowledge of the participants. In the past, the instructor made projects more open-ended by asking preservice teachers to choose something to teach for their certificate area. However, this open-ended assignment overwhelmed freshmen who had very limited content knowledge, especially when they were taking general education classes, instead of their content area classes. Hence, the instructor decided to make the project semi close-ended where students were to select a hero from their subject areas.

The task was to create a presentational material that represents a hero, or someone who made a significant contribution to their area of certification. The instructor chose the task because the research participants would be likely to have some prior knowledge about the person that they would like to present about, and if 
they chose someone that they have positive emotions about, they would likely be motivated to do further research. The students were asked to determine their heroes of their teaching certificate area, research about their heroes, and make something to present their heroes to the class. Any subject area has someone who made a significant contribution. When each student identifies someone he or she looks up to, he/she is likely to have positive emotion on the topic. Internal motivation facilitates "active engagement, deeper understanding, and a desire to learn more" (Trilling \& Fadel, 2009, p.33).

Since the project required the participants to look up new methods and tutorials, a training to ensure that they have this skill was necessary. Hence, they completed Google Fundamentals Training Level 1 (https://teachercenter.withgoogle.com/fundamentals/course) prior to the project. They participated in Unit \#1 (Get Ready to Use Technology in Classroom) and Unit \#2 (Expand Your Access to Help and Learning). When an open-ended task is assigned, it is important to show sample products in the beginning of the project. The instructor presented heroes in different subject areas using a variety of technology tools. At this stage, the concept of the makerspace was introduced to the students. The instructor showed two examples:

The first example was made for world language education. The instructor visited a native speaker of Spanish with her iPhone, and recorded a brief biography of Roberto Clemente. Clemente was a Puerto Rican baseball player who played for the Pittsburgh Pirates. He not only overcame racism to become a popular baseball player in the United States, but also made an impact on Puerto Rican Society. The instructor uploaded the biography recording to Dropbox, and set the audio file to be publically accessible. She then used Cricut, a cutting machine, to create 3-D model of Roberto Clemente, representing a baseball player bearing number 21, a Puerto Rican flag, and a bridge. The instructor then created a QR code to access the Clemente's biography recording and the Spanish language biography from Smithsonian Institution Traveling Exhibition Service (http://www.robertoclemente.si.edu/spanish/virtual_legacy.htm). She pasted the QR codes to the 3-D model.

The second example was made for social studies education majors. The process of creating the example started with a story about Marcus Tullius Cicero attempting to defend the ideal of the Republic when the climate of Roman politics was moving towards dictatorship. The story ended with Cicero's assassination by Mark Anthony. The instructor made the story into a digital movie using Windows Movie Maker, and uploaded it to YouTube.

As the instructor showed two examples, she explained that research on the content was the driving force for making both. She advised the students to spend time on increasing content knowledge before selecting which tools to use. She also explained that since the objective is to explore innovation and creativity, everyone would be free to choose materials that they want to use. Students were also invited to seek out help in adding an audio recording, a video, and a QR code to their work. The instructor also informed the students that they will have access to a Cricut cutting machine, cardstock, vinyl, scissors, glue, color pencil, s paper cutter, and s laminator. Students reported to two class sessions where the instructor set up the makerspace. They then presented their heroes to the class.

\subsubsection{Data Analysis}

Research question 1: Do education majors increase their knowledge about makerspace after the instruction?

Paired sample t-tests were calculated in order to compare values between pre-instructional time and post-instructional time. Table 1 shows the result of the t-tests.

Table 1. Mean comparisons between pre-instructional and post-instructional self-assessments

\begin{tabular}{ccccccc}
\hline & $\mathrm{n}$ & $\begin{array}{c}\text { Mean Pre } \\
(\mathrm{SD})\end{array}$ & $\begin{array}{c}\text { Mean Post } \\
(\mathrm{SD})\end{array}$ & $\begin{array}{c}\text { Mean } \\
\text { Post- Mean Pre }\end{array}$ & $\mathrm{t}$ & $\begin{array}{c}\text { Sig. } \\
(2 \text { tailed })\end{array}$ \\
\hline I know what a makerspace is. & 26 & $\begin{array}{c}2.4231 \\
(1.30)\end{array}$ & $\begin{array}{c}4.6923 \\
(.68)\end{array}$ & 2.2692 & 8.092 & .000 \\
I know how to design a makerspace. & 26 & $\begin{array}{c}2.1538 \\
(1.19)\end{array}$ & $\begin{array}{c}4.5769 \\
(.70)\end{array}$ & 2.4231 & 9.726 & .000 \\
I know how to use a makerspace. & 26 & $\begin{array}{c}2.3462 \\
(1.16)\end{array}$ & $\begin{array}{c}4.6538 \\
(.69)\end{array}$ & 2.3076 & 9.129 & .000 \\
\hline
\end{tabular}

The result of the t-tests indicate that the concept of makerspace was a new idea to the research participants. All names that are used in this manuscript are pseudonyms. Mary stated, 
"Before this assignment, I was unaware of makerspace and how it works. This tool essentially brings ideas to life, encourages collaborations, and promotes creativity. I am now more familiar with this kind of environment and it is something I would implement into my own classroom. Reading and exploring the makerspace website to find ideas heled to enhance my understanding."

Research question 2: What type of tools do research participants choose to use?

In this study, the participants freely chose to use tools that they wanted to use. Table 2 shows tools and materials that the participants chose to use to create their hero presentation.

Table 2. Tools and materials used

\begin{tabular}{cc}
\hline Tools used & Frequency \\
\hline Internet search for content & 12 \\
Construction paper & 5 \\
Glue & 4 \\
Google Docs & 3 \\
Scissors & 3 \\
Microsoft word & 2 \\
iMovie & 2 \\
Cricut Design Space & 2 \\
Laminator & 2 \\
Popsicle sticks & 1 \\
Paper trimmer & 1 \\
Paint & 1 \\
Styrofoam balls & 1 \\
Drawing supplies & 1 \\
QR code maker & 1 \\
PowerPoint (to create a digital movie) & 1 \\
\hline
\end{tabular}

The data indicates that 12 out of 26 students said that they used the Internet to search for content. The total number exceeds 26 , the number of research participants, because one person used multiple items to complete his or her project.

Research question 3: Will there be research participants who use tools that they have never used without the instructor's assistance?

This group represent early adopters. Reflective writing was used to answer this question. Students' statements in this section represent the research participants who tried new tools or methods. Linsey made a movie using PowerPoint. Although she knew how to use PowerPoint, she did not know how to create a movie and published it on YouTube. She decided that she wanted to create a video about Sir Isaac Newton when she saw the instructor's sample movie about Marcus Tullius Cicero. However, while the instructor told the class that she made her movie with Windows Movie Maker, it was Linsey's initiative to turn PowerPoint slides into a movie. She wrote, "I knew how to upload videos to YouTube prior to this project. However, I did not know how to turn a PowerPoint into a slide show and create voice narrations. I had to turn to the Internet to find instructions on how to do so. .... I am always open to new and exciting technologies or tools."

Janet also taught herself how to make a movie, but she chose iMovie. She "was not very familiar with it. This project gave me the opportunity to really learn how to use iMovie effectively and efficiently and I now know how to use it better than I did." Jackson also used iMovie for the first time. He stated, "Using iMover was a totally new experience. I had never uploaded a video to YouTuble. Lastly, I had never had the need to record audio on my laptop, so I was unfamiliar with how to use the laptop microphone. .... While learning how to use iMovie was a slight struggle at times, I was able to learn enough to create a decent finished product."

Beth and Amber stated that they used Google search, YouTube video, and Pinterest to look for ideas prior to deciding which tools they wanted to use. Amber said, "I had to research and look up tutorials on how to create the project that I was working on."

Melinda, a French Education Major, took the idea of combining Cricut and a QR code from the instructor's Roberto Clemente presentation. She created a graphic representation that was structured similar to the one that the instructor presented, but chose to present about Charles Aznavour, a French Armenian singer. She created 2 QR codes that allow the audience to access Charles Aznavour's 2 famous songs. She said she regularly used YouTube and Pinterest when she needs to learn something new, and successfully completed the project without the instructor's assistance. 
Elaine, a French and English Education Major, decided that she wanted to create something about Antoine de Saint-Exupéry, a French writer. She wanted to create a planet mobile to represent scenes from Le Petit Prince, Saint-Exupéry's famous book. She stated, "Although I did not use any tool out of the ordinary, I did have to research and look up tutorials on how to create the project that I was working on. I never made a planet mobile: therefore, this project created a new experience for me."

Research question 4: Will there be research participants who use tools that they have never tried with the instructor's assistance?

This group belong ether in early majority, according to Rogers' framework. Mary stated, "Because I became familiar with makerspace in class and motivated to take advantage of this workspace since I knew what I was getting into. If I was unaware of how this tool worked, I many have been hesitant to utilize it and may have missed out on a great, creative opportunity."

Jillian, a math education major, became interested in using Cricut Design Space when she saw the instructor's sample during the project explanation. She is a math education major, and decided to create a display on Pythagoras. She stated,

"I did not know how to use the Cricut Design Space or the laminator, but through this project I was able to learn how to use two different tools that I would have never had the chance to learn. I really liked Dr. XXX's Roberto Clemente example presentation. She also explained how she used a Cricut for the images. Knowing what a Cricut was, but now how to use it I knew would be a challenge. I wanted to challenge myself and use something that I have never used before. I also wanted to use the laminator because I saw how nice Dr. XXX's project looked, and I knew in the future I would be using a laminator in my class. ...The Cricut took a few moments of trial and error, but I believe I learned a lot from that experience. I was able to use my problem-solving skills to discover how to use the program, and how to troubleshoot."

David, who is "open to learning about new tools" decided to use Circuit after instructor suggested it. He made a visual presentation of Joshua Chamberlain, capturing his leadership during the Battle of Gettysburg in the American Civil War. The instructor recommended that he add an eagle shaped cut out of gold vinyl and helped him use Cricut. He stated,

"I used this tool because it helped me to create a nice eye-catching piece for my project. The precise cuts and glossy sheen of the vinyl material make it stand out among the other parts of the project, and crated a wonderful centerpiece for the project that other methods may not have achieved. I honestly say that it helped immensely."

Research question 5: Will there be research participants who do not use tools that they have never used even when assistance is available?

Statements in this group showed the characteristics of late majority or laggards. Late majority can be someone who did not try to do something new during the project, but wished they had tried after they saw peers' successes. Heather wrote,

"I wanted to spend time on the small details of the project instead of trying to learn something brand new and get caught up in the process. With that being said, after walking around and seeing everyone else's project I have learned so much and cannot wait to try out some of their ideas... after seeing all of the other projects I am inspired in so many ways."

Kim said,

"I feel like I could have done better by trying to use a tool like Cricut. Cricut is something I have never used before and wish I would have tried it." Megan said, "I could have been a little more creative and gone out of my comfort zone to create this project."

On the other hand, laggards are the ones who refuse to try new tools or methods even after they see peers' successes. Geoff explained he choose to use the material because "they were familiar to me ... and are very convenient." Mike said, "I tend to stay away from exploring new tools because of trying to learn how to use it is sometimes difficult and I would rather use that I know and works best for me. Makes it easier on me and being able to get things done efficiently without the headache of trying to learn how to use something new."

Research Question 6: Do perceived usefulness and perceived ease of use influence the decision to use new tools?

Comments about perceived usefulness included (the author italicized relevant text):

- " "I used the laminator for the finishing touches and to enhance the quality of my work."

- "I thought that QR code will be useful. If I had not seen the model of Roberto Clemente that was presented to the class I would have had no idea that I could have done that and I would have not used it in my project." 
- Comments by Jillian and David in Research Question 4 indicate that they decided to use Cricut because they saw the use of the cutting machine improve the quality of a finished product.

Comments about perceived ease of use included (the author italicized relevant text):

- "I was able to work out how to use the QR Code Maker with ease."

- $\quad$ "I tend to stay away from exploring new tools because trying to learn how to use it is sometimes difficult."

- $\quad$ "Cricut seems complicated [hence, I did not use it]; I would like to become more familiar with it. A fellow student taught me how to use the laminating machine. I liked this tool because it is simple, yet it makes a project appear professional."

However, some strived to keep trying when they encountered difficulties. For example, Janet's quote in Research Question 3 shows, “... While learning how to use iMovie was a slight struggle at times, I was able to learn enough to create a decent finished product."

\section{CONCLUSION}

\subsection{Implications}

This research used Diffusion of Innovation theory and Technology Acceptance Model as frameworks. According to Rogers, the decision making process requires mental work. The framework also implies that adopters tend to have some tolerance to uncertainty. Although Rogers suggested the framework decades ago, his work is still applicable because human nature has not changed. There are those who enjoy the challenge of learning something new, and those who avoid the mental work. Likewise, some have higher tolerance to uncertainty. In this study, two participants saw that the instructor used Movie Maker to create Marcus Tullius Cicero's biography movie, and decided to make a digital movie. One used iMovie, and the other turned PowerPoint into a movie. Both had never created a digital movie before, but they searched for tutorials from YouTube and Pinterest and taught themselves how to create a digital movie. One participant used Cricut and QR code creator for the first time, and completed the project without the instructor's assistance. They represent the research participants who were willing to seek out new ideas and teach themselves.

Two participants reflected that they decided to used Cricut after they saw the Roberto Clemente 3D model. They had access to a laptop with Cricut Design Space, machine, and a variety of cardstock paper and vinyl to cut with the machine. They completed their project with instructor's help to use the machine. They represent the population that is willing to adopt innovation when assistance is available.

The third group decided not to try anything new, but wished they had tried after they saw peers' successful adoption. statements from this group has the characteristics of late adopters. They did want to spend the time to learn Cricut while they used a makerspace. However, after they viewed peer's finished products, they wished they had used the tool. Finally, the fourth group self-reflected that they prefer to stay in their comfort zone, and would like to avoid, the "headache of trying to learn how to use something new." The fourth group has the characteristics of laggards. The research participants' comments support the conclusion that perceived usefulness and perceived ease of use influence the decision to adopt a new technology tool. However, attitudes about the perceived ease of use differs among those who are willing to learn on their own, those who learned to use a tool with assistance, and the who avoided using new tools.

\subsection{Limitations}

This research used Diffusion of Innovation theory as a framework. According to Rogers, the decision making process require mental work. The framework also imply that adopters tend to have some tolerance to uncertainty, and the motivation to seek innovation (Rogers, 1983). This research showed that not all are willing to try new tools or methods when they become available. However, the research did not measure personal attributes, such as the willingness to make cognitive effort, tolerance to uncertainty, and the motivation to seek out new tools or methods. It is suggested, therefore, these personal attributes should be measured in future studies. 
This research also used the Technology Acceptance Model, which suggests that the perceived usefulness and perceived ease of use of technology influence the decision to adopt a new technology tool. While some studies, such as Çakiroglu, Gökoglu, \& Öztürk (2017) and Joo, Park, \& Lim (2018) use surveys to measure perceived usefulness and perceived ease of use, the present study did not because the participants were encouraged to freely choose materials and tools. Collecting data on perceived usefulness and perceived ease of use of specific maker space tools, and examining how self-efficacy influences perceived ease of use, is a meaningful area of future study.

\section{REFERENCES}

Bandura, A. 1994. Self-efficacy. In V. S. Ramachaudran (Ed.), Encyclopedia of human behavior (Vol. 4, pp. 71-81). New York: Academic Press.

Çakiroglu, Ü. Gökoglu, S., \& Öztürk, M. 2017. Pre-service computer teachers' tendencies towards the use of mobile technologies: A technology acceptance model perspective. European Journal of Open, Distance and E-Learning, 20 (1). 175-190.

Chung, H. and Kim, H., 2010. Implementing professional standards in teacher preparation programs in the United States: Preservice teachers' understanding of teaching standards. KEDI Journal of Educational Policy, Vol. 7, No. 2, pp.355-377.

Davis, F. D. 1989. Perceived usefulness, perceived ease of use, and user acceptance of information technology. MIS Quarterly, 13(3), 319-339.

Flavell, H., Harris, C., Price, C., Logan, E., \& Peterson, S. 2019. Empowering academics to be adaptive with eLerning technologies: An exploratory case study. Australasian Journal of Educational Technology, 35(1), 1-15.

International Society for Technology in education., 2017. ISTE Standards for Educators. Retrieved from https://www.iste.org/standards/for-educators

Joo, Y J., Park, S., Lim, E. 2018. Factors influencing preservice teachers' intention to use technology: TPACK, teacher self-efficacy, and technology acceptance model. Educational Technology \& Society, 21(3), 48-59.

Krueger, N., April 2019. Innovate, iterate, educate: Sometimes teachers' small ideas make the biggest difference. Empowered Learner, Vol. 2, No. 4. Pp/ 17-21.

Kukul,V., Ünal, M., Karataş, S., Kılıç Çakmak, E., Yılmaz, A. and Ömeroğlu, E. 2018. Analysis of teachers'opinions in the context of acceptance of technology, Journal of Kirşehir Education Faculty, 19(3), 2055-2067.

Mann, L., 2018, Making a place for makerspaces in information literacy. Reference \& User Services Quarterly, Vol. 58, No. 2. pp.82-86.

Maughan, S., Dec. 14, 2018. School \& library spotlight fall 2018: Q \& A with Nicholas Provenzano. Publishers Weekly, Retrieved from https://www.publishersweekly.com/pw/by-topic/childrens/childrens-authors/article/78847-schoollibrary-spotlight-fall-2018-q-a-with-nicholas-provenzano.html

McQuinn. C., 2018, The brain science of making. School Library Journal. Retrieved from https://www.slj.com/?detailStory=brain-science-of-making

Muilenburg, L. Y., and Berge, Z. L., 2015. Revisiting teacher preparation: Responding to technology transience in the educational setting. The Quarterly Review of Distance Education, Vol. 16, No. 2, pp 93-105.

Murray, F. B., 2001. From consensus standards to evidence of claims: Assessment and accreditation in the case of teacher education. New Directions for Higher Education, Vol. 113, pp. 49-66.

Passehl-Stoddart, E., Velte, A., Henrich, K. J. and Gaines, A. M., 2018. History in the making: Outreach and collaboration between special collections and makerspaces. Collaborative Librarianship, Vol. 10, No. 2, pp. 133-149.

Rogers, E. M., 1983. Diffusion of Innovations (3rd Ed.). The Free Press, New York, USA.

Shittu, A. T., Kareem, B. W., Obielodan, O. O., \& Fakomogbon. 2017. Investigating predictors of pre-service science teachers' behavioral intention toward e-resources for teaching. Contemporary Educational Technology, 8(2), $142-157$.

Trilling, B. and Fadel, C., 2009. 21st century skills. Learning for life in our times. Jossey-Bass, San Francisco, USA.

Trust, T. Maloy, R. W., and Edwards, S., 2018. Learning through making: Emerging and expanding design for college classes. TechTrends, Vol. 62, pp.19-28. doi: 10.1007/s11528-017-0214-0 